\title{
Stability-Indicating HPTLC Method for Determination of Duloxetine Hydrochloride in Bulk Drug and Tablet Formulation
}

\author{
Sheikh Shahnawaz, ${ }^{1}$ Abdul Wadood Siddiqui, ${ }^{1}$ Mir Tariq Masroor, ${ }^{2}$ and Vandana Arora ${ }^{1}$ \\ ${ }^{1}$ Department of Pharmacy, Lloyd College, Knowledge Park II, Greater Noida 201306, India \\ ${ }^{2}$ Ranbaxy Research Labs, Haryana, Gurgaon 122001, India \\ Correspondence should be addressed to Sheikh Shahnawaz, sshahnawaz78@gmail.com
}

Received 18 June 2011; Accepted 21 July 2011

Academic Editor: Antonio Martín-Esteban

Copyright (C) 2011 Sheikh Shahnawaz et al. This is an open access article distributed under the Creative Commons Attribution License, which permits unrestricted use, distribution, and reproduction in any medium, provided the original work is properly cited.

\begin{abstract}
A simple, accurate, precise, sensitive, selective, and stability-indicating high-performance thin-layer chromatographic method was developed and validated for determination of duloxetine hydrochloride both in bulk drug as well as in tablet formulation. The stationary phase used in our method consisted of HPTLC aluminum plates precoated with silica gel 60F-254, while, chloroform : methanol $(8: 2, \mathrm{v} / \mathrm{v})$ was used as binary mobile phase. These chromatographic conditions eluted the drug effectively, and distinct compact spots were seen, (Rf, retardation factor, value $(0.42 \pm 0.20)$. Densitometric determination of duloxetine hydrochloride was carried out in the absorbance mode at a wavelength of $217 \mathrm{~nm}$. The mean value of corelation coefficient; slope and intercept were $0.9962 \pm 0.0015,121.54 \pm 0.61$, and $987.3 \pm 6.17$, in the amount range of 600-2000 ng (nanogram) per spot, respectively. Stress testing validation were performed as per the guidelines of International Conference on Harmonization $(\mathrm{ICH})$ and drug was subjected to stress conditions like acid-hydrolysis, alkali-hydrolysis, oxidation, and thermal degradation. As the method effectively separated the active drug from its degradation products, it can be employed as a stability-indicating assay method (SIAM) for identification and quantitative determination of duloxetine $\mathrm{HCl}$ in bulk drug and tablet dosage formulation.
\end{abstract}

\section{Introduction}

Duloxetine hydrochloride designated in IUPAC as $(+)$ (S)-N-methyl-gamma-(1-naphthyloxy)-2- thiophenepropylamine hydrochloride (Figure 1) is an agent indicated for the treatment of major depressive disorder (MDD), [1]. The years from 1990 through 1999 were termed the "Decade of the Brain" by the Library of Congress and the National Institute of Mental Health. Since that decade, our understanding of depression has grown enormously. It is estimated that Major Depressive Disorder (MDD) affects 18 million people in the United States and 340 million people worldwide.

It is also indicated for the management of neuropathic pain associated with diabetic peripheral neuropathy [2]. Duloxetine has also been thoroughly experimented to be associated with smoking cessation, and research is going on [3]. A significant reduction in the frequency of incontinence episodes and a resulting improvement in quality of life were found when duloxetine was given to a group of women with stress urinary incontinence. Duloxetine $80 \mathrm{mg}$, dosed at $40 \mathrm{mg}$ BID, reduced the frequency of episodes by $64 \%$ to $100 \%$ in half of the women who took the drug, compared with a $41 \%$ median reduction seen in a group of women on placebo [4]. Duloxetine is a potent reuptake inhibitor of both neuronal serotonin as well as nor-epinephrine but a less potent inhibitor of dopamine. Duloxetine has no significant affinity for dopaminergic, adrenergic, cholinergic, histaminergic, opioid, glutamate, and GABA receptors in vitro. Duloxetine does not inhibit monoamine oxidase (MAO) [5].

Literature survey revealed many analytical methods for the estimation of duloxetine hydrochloride $[6,7]$, however, no HPTLC method has so far been developed for bulk and tablet formulations.

HPTLC method is becoming a routine analysis technique due to its advantages. The major advantage is that, several 


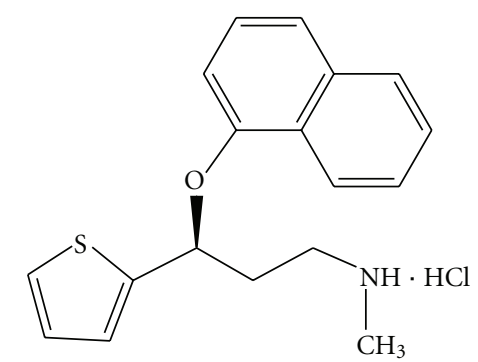

FIgURE 1: Structure of Duloxetine $\mathrm{HCl}$.

samples can be run simultaneously using a small quantity of mobile phase unlike HPLC, thereby minimizing the analysis cost and time. The aim of this work was to develop an accurate, specific, repeatable, and stability-indicating method for the determination of duloxetine $\mathrm{HCl}$ in the presence of its degradation products and related impurities as per ICH guidelines [8].

\section{Experimental}

2.1. Materials. Duloxetine $\mathrm{HCl}$ was received as a gift from Zydus Cadila, Ahmedabad, India. The other chemicals and reagents used were of analytical grade and were purchased from Rankem and Qualigens, India.

2.1.1. HPTLC Instrumentation. HPTLC instrumentation consisted of Camag Linomat IV, and samples were spotted in the form of bands of width $5 \mathrm{~mm}$ using Camag microlitre syringe (constant application rate of $1 \mu \mathrm{L} \mathrm{s}^{-1}$ ) on Merck silica gel precoated HPTLC aluminum plate $60 \mathrm{~F} 254,(20 * 10 \mathrm{~cm}$, $250 \mu$ thickness). The slit dimensions of $5 \mathrm{~mm} \times 0.45 \mathrm{~mm}$ and a scanning speed of $5 \mathrm{~mm} \mathrm{~s}^{-1}$ were found to be optimum. The solvent system employed consisted of chloroform: methanol $\left(\mathrm{CHCl}_{3}: \mathrm{CH}_{3} \mathrm{OH}, 80: 20 \mathrm{v} / \mathrm{v}\right)$. Ascending development technique was carried out in twin trough glass chamber previously saturated with the mobile phase. The saturation time for mobile phase was found to be $40 \mathrm{~min}$ at room temperature. The length of solvent front allowed to move along the vertical length of HPTLC plate was $8.5 \mathrm{~cm}$. The HPTLC plates were dried in a current of hot air with the help of an air-drier. The densitometric scanning was performed on Camag TLC scanner III in the absorbance mode at a wavelength of $217 \mathrm{~nm}$, employing deuterium lamp.

2.1.2. Calibration Curves of Duloxetine Hydrochloride. A stock solution of duloxetine $\mathrm{HCl}\left(100 \mu \mathrm{g} \mathrm{mL}^{-1}\right)$ was prepared in methanol, and from this $6,8,10,12,16$, and $20 \mu \mathrm{L}$ were spotted on TLC plate to obtain a concentration of 600 , $800,1000,1200,1600$, and $2000 \mathrm{ng}$ per spot, respectively. Linearity was also determined over the range of 600-2000 ng per spot, and data obtained was subjected to linear leastsquare regression analysis.

\subsection{Method Validation}

2.2.1. Precision. Six replicates of same concentration (600 ng per spot of Duloxetine $\mathrm{HCl}$ ) were checked for repeatability of the sample application and determination of peak area. The results qualify the requirements of \%RSD. of peak area of Duloxetine $\mathrm{HCl}$. The intraday and interday variation for the determination of Duloxetine $\mathrm{HCl}$ was carried out at three different concentration levels of 600,800 , and $1000 \mathrm{ng}$ per spot.

2.2.2. Robustness of the Method. The mobile phase volume and temperature were varied, and effect on the quality of chromatograms was recorded. The mobile phase ratios of chloroform:methanol was deliberately changed $(2: 8,4: 6$, and $6: 4 \mathrm{v} / \mathrm{v}$ ), and its effect on results was seen at different concentrations of 600,800 , and $1000 \mathrm{ng}$ per spot.

2.2.3. Limit of Detection and Limit of Quantification. The background noise of blank sample was determined by analyzing pure methanol, and then signal-to-noise ratio, limit of detection (LOD) and limit of quantification (LOQ) were determined by spotting a minimum concentration of duloxetine $\mathrm{HCl}$ (starting from $20 \mathrm{ng}$ per spot, and then concentration was gradually increased).

2.2.4. Recovery Studies. The preanalysed samples were spiked with additional 80,100 , and $120 \%$ of the standard Duloxetine $\mathrm{HCl}$, and the mixtures were reanalyzed by this method. The experiment was repeated in triplicate, and percentage recoveries in formulations were determined.

2.2.5. Analysis of the Tablet Formulation. The drug content in duloxetine $\mathrm{HCl}$ in tablet formulation (Tablet, Symbal, label claim: $30 \mathrm{mg}$ per tablet) was determined. Twenty tablets were powdered, and then a powder equivalent to $20 \mathrm{mg}$ was weighed and extracted with methanol. To ensure complete extraction, it was sonicated for $15 \mathrm{~min}$, and then solution was serially diluted with methanol to get a concentration of $0.1 \mu \mathrm{g} \mu \mathrm{L}^{-1}$. The resulting solution was filtered, and then $10 \mu \mathrm{L}$, that is, $1000 \mathrm{ng}$ per spot solution was applied on TLC plate followed by development and scanning.

2.2.6. Forced Degradation of Duloxetine Hydrochloride. A stock solution was prepared by dissolving $10 \mathrm{mg}$ of Duloxetine $\mathrm{HCl}$ in $100 \mathrm{~mL}$ of methanol, and $20 \mathrm{~mL}$ of this solution was utilized for forced degradation studies.

\subsubsection{Preparation of Acid-Induced and Alkali-Induced Degra-} dation Product. To $20 \mathrm{~mL}$ of methanolic stock solution, $10 \mathrm{~mL}$ each of $2 \mathrm{M} \mathrm{NaOH}$ (for 8 hours) and $0.5 \mathrm{M} \mathrm{HCl}$ (for 4 hours) were added separately at room temperature. A sample was taken every hour and was neutralized (using standard $\mathrm{pH}$ paper). The concentration of drug equivalent to $1000 \mathrm{ng}$ per spot of duloxetine was immediately subjected to HPTLC determination to find out the effect of stress conditions. The forced degradation was performed in the dark to prevent the possible degradation by light. 
TABLE 1: Linear regression data (ng per spot) for the calibration curves ${ }^{\mathrm{a}}$.

\begin{tabular}{lccccc}
\hline Linearity range & $r \pm \mathrm{SD}$ & Slope \pm SD & Confidence limit of slope $^{\mathrm{b}}$ & Intercept \pm S.D. Confidence limit of intercept $^{\mathrm{b}}$ \\
\hline $600-2000$ & $0.9962 \pm 0.0015$ & $121.54 \pm 0.61$ & $120.98-122.08$ & $987.31 \pm 6.17$ & $982.14-992.92$ \\
\hline
\end{tabular}

${ }^{\mathrm{a}} n=3,{ }^{\mathrm{b}} 95 \%$ confidence limit.

TABLE 2: Intraday and interday precision of HPTLC method.

\begin{tabular}{lcccccccc}
\hline $\begin{array}{l}\text { Amount } \\
\text { (ng per spot) }\end{array}$ & \multicolumn{3}{c}{ Intraday precision $(n=6)$} & \multicolumn{4}{c}{ Interday precision $(n=6)$} \\
& Mean area & SD & \%RSD & SE & Mean area & SD & \%RSD & SE \\
\hline 600 & 5403.23 & 24.43 & 0.45 & 9.97 & 5356.38 & 25.23 & 0.47 & 10.30 \\
800 & 7209.17 & 22.69 & 0.31 & 9.26 & 7154.16 & 24.29 & 0.34 \\
1000 & 9015.28 & 21.79 & 0.24 & 8.89 & 8928.81 & 22.16 & 0.25 & 9.04 \\
\hline
\end{tabular}

SD: standard deviation; SE: standard error.

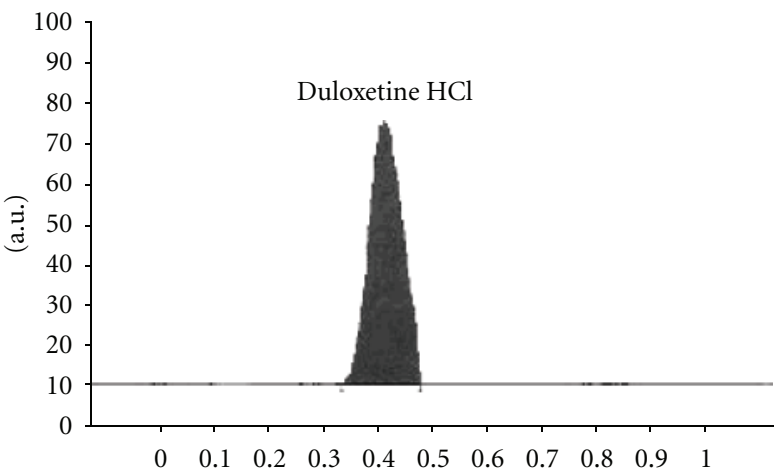

Figure 2: A typical HPTLC chromatogram of duloxetine hydrochloride $\left(R_{f}=0.42\right)$.

2.2.8. Preparation of Hydrogen Peroxide-Induced Degradation Product. To $20 \mathrm{~mL}$ of methanolic stock solution, $10 \mathrm{~mL}$ of hydrogen peroxide $(30 \%, \mathrm{v} / \mathrm{v})$ was added at the room temperature. This solution was then heated in boiling water bath for 8 hours to remove the excess of hydrogen peroxide. The resultant solution (1000 ng per spot) was applied on TLC plate, and the chromatograms were recorded.

2.2.9. Thermal Degradation Product. The thermal degradation of the drug was carried out by heating the stock solutions at $70^{\circ} \mathrm{C}$ for 5 hours. The resultant solutions were appropriately diluted every hour, 1000 ng per spot was applied on TLC plate, and chromatograms were recorded.

\section{Results and Discussion}

3.1. Development of the Optimum Mobile Phase. The main purpose of our HPTLC method development and validation was to devise a stability-indicating assay method. The analysis of both pure drug as well as of degraded products were tried in different solvent systems. Initially combinations of butanol, hexane, toluene, and acetic acid with varying proportions were tried, but finally, the mobile phase consisting

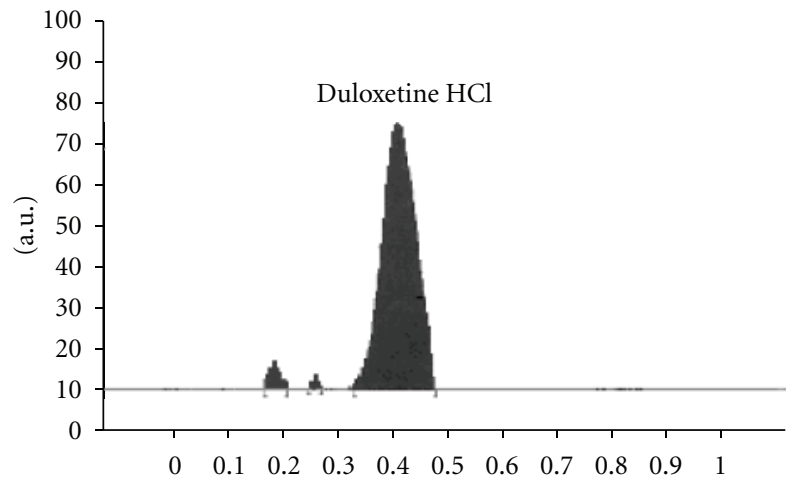

FIGURE 3: A HPTLC chromatogram of alkali-treated duloxetine hydrochloride.

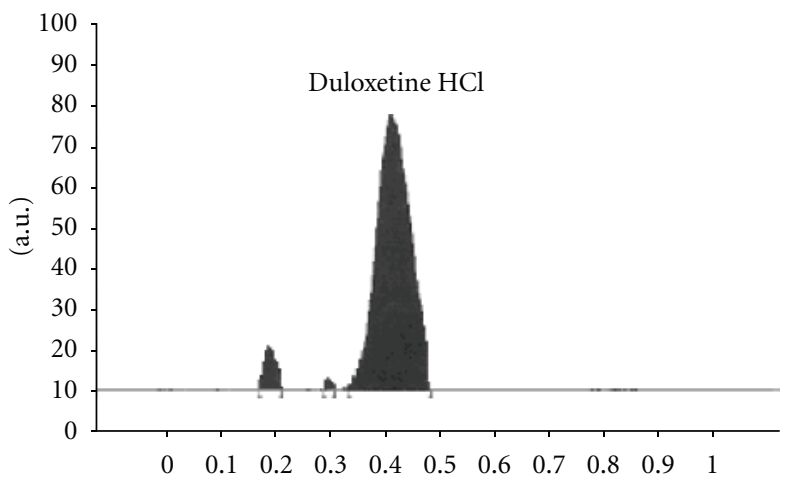

FIgURE 4: A HPTLC chromatogram of hydrogen peroxide-treated duloxetine hydrochloride.

of chloroform: methanol $(8: 2, \mathrm{v} / \mathrm{v})$ gave well-defined spots having good resolutions. The optimum development time was found to be $40 \mathrm{~min}$ at room temperature.

3.2. Calibration Curves. The linear regression data for the calibration curves $(n=3)$ as shown in Table 1 correlated a 
TABLE 3: Recovery studies of duloxetine hydrochloride.

\begin{tabular}{lcccc}
\hline Excess drug spiked to Preanalyzed drug $(\%)^{*}$ & Drug content (ng per spot) & Recovery $(\%)$ & \%RSD & SE \\
\hline 0 & 600 & 99.36 & 0.55 & 0.45 \\
80 & 1080 & 100.49 & 0.78 & 0.64 \\
100 & 1200 & 100.45 & 0.65 & 0.53 \\
120 & 1420 & 100.41 & 0.62 & 0.51 \\
\hline
\end{tabular}

$*(n=6)$.

TABLE 4: Stress degradation of duloxetine hydrochloride.

\begin{tabular}{lcc}
\hline Stress conditions* & $\begin{array}{c}\text { Degradation } \\
\text { products } \\
\left(R_{f} \text { value }\right)\end{array}$ & $\begin{array}{c}\text { Recovery } \\
(\%)\end{array}$ \\
\hline $0.5 \mathrm{M} \mathrm{HCl} \mathrm{RT}(4 \mathrm{~h})$ & $2,(0.12,0.21)$ & $83.13 \%$ \\
$2.0 \mathrm{~N} \mathrm{NaOH} \mathrm{RT}(8 \mathrm{~h})$ & $2,(0.19,0.28)$ & $92.28 \%$ \\
$30 \% \mathrm{H}_{2} \mathrm{O}_{2} \mathrm{RT}(8 \mathrm{~h})$ & $2,(0.19,0.31)$ & $91.11 \%$ \\
Heat $\left(70^{\circ} \mathrm{C}\right)(5 \mathrm{~h})$ & $1,(0.24)$ & $94.45 \%$ \\
\hline
\end{tabular}

* $(n=3), \mathrm{RT}$ (room temperature), h (hours).

TABLE 5: Summary of validation parameters.

\begin{tabular}{lc}
\hline Parameter & Data \\
\hline Linearity range & $600-2000$ (ng per spot) \\
Limit of detection & 100 (ng per spot) \\
Limit of quantification & 350 (ng per spot) \\
Correlation coefficient & $0.9962 \pm 0.0015$ \\
Recovery (\%) & $99.85 \pm 0.60$ \\
Precision (\%RSD) & \\
Interday & 0.35 \\
Intraday & 0.33 \\
\hline
\end{tabular}

good linear relationship over the concentration range 6002000 ng per spot. No significant differences were observed in the slopes of standard curves.

\subsection{Validation of the Method}

3.3.1. Precision. The repeatability of sample application and measurement of peak area were expressed in terms of relative standard deviation (\%RSD) and was found to be less than $0.1 \%$. The results depicted in Table 2 revealed intraday and interday variation of duloxetine hydrochloride at three different concentration levels of 600,800 , and 1000 ng per spot.

3.3.2. Robustness of the Method. Our method was robust, since $\%$ RSD was found to be less than $2.0 \%$ after introducing deliberate small changes in temperatures and mobile phase ratio.

3.3.3. LOD and LOQ. As per the ICH guidelines, signal-tonoise ratio having values of 3 and 10 were considered as LOD and LOQ, respectively. The LOD and LOQ were found to be 100 and $350 \mathrm{ng}$ per spot, respectively.

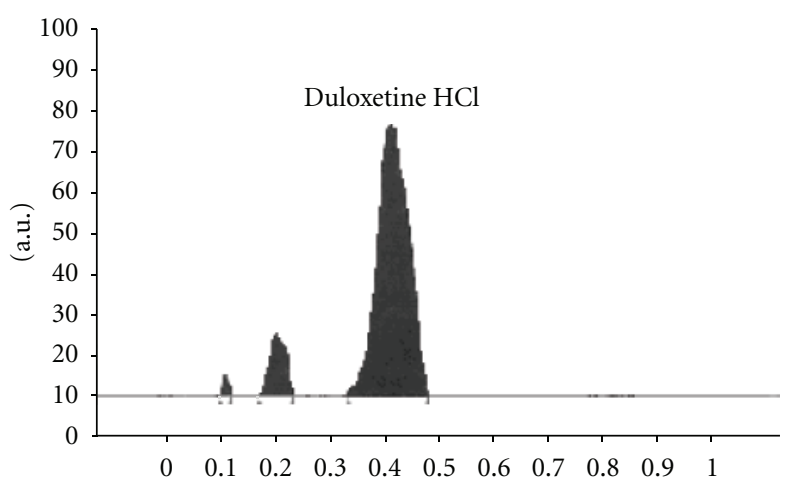

FIGURE 5: A HPTLC chromatogram of acid-treated duloxetine hydrochloride.

3.3.4. Recovery Studies. The proposed method was utilized for extraction studies, and subsequent estimation of duloxetine hydrochloride in pharmaceutical dosage forms after spiking a preanalysed sample with 80,100 , and $120 \%$ of additional drug. The recoveries were found to be between 99-101\% as listed in Table 3.

3.3.5. Analysis of the Tablet Formulation. A single peak was observed in the chromatogram obtained in the analysis of drug samples extracted from tablets, and no additional interfering peak(s) were observed due to the presence of excipients in the tablets. The drug content was found to be $99.28 \%$ with a $\%$ RSD of $0.48 \%$.

3.3.6. Stability-Indicating Property. The method distinctively separated the degraded products of duloxetine $\mathrm{HCl}$ due to acid, base, oxidative, and thermal treatments. The chromatograms of degraded products were well resolved from the chromatograms of drug as shown in Figures 2, 3, 4, 5 and 6. The degradation product(s) formed, $R_{f}$, and percentage recoveries calculated are shown in Table 4 . The summary of validation parameters is shown in Table 5 .

\section{Conclusion}

The proposed HPTLC method was developed and validated for precision, specificity, and accuracy. The method was applicable both for determination of bulk drug as well as the tablet formulation. The method separates the drug from its degradation products, and as such it can be described as a stability-indicating assay method (SIAM). 


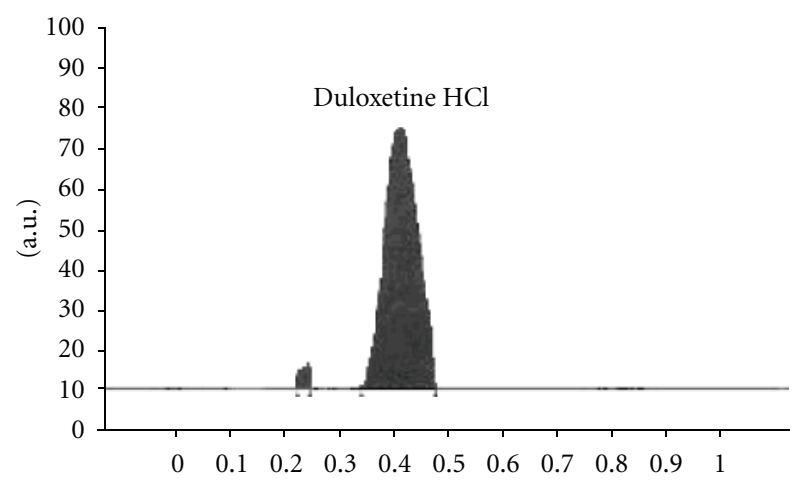

FIGURE 6: A HPTLC chromatogram of thermally degraded duloxetine hydrochloride.

\section{Acknowledgment}

The authors thank Zydus Cadila, Ahmedabad, India, for providing gift sample of duloxetine.

\section{References}

[1] L. Viktrup and R. C. Bump, "Pharmacological agents used for the treatment of stress urinary incontinence in women," Current Medical Research and Opinion, vol. 19, no. 6, pp. 485490, 2003.

[2] J. F. Wernicke, Y. L. Pritchett, D. N. D'Souza et al., "A randomized controlled trial of duloxetine in diabetic peripheral neuropathic pain," Neurology, vol. 67, no. 8, pp. 1411-1420, 2006.

[3] W. A. Marcil and F. Petty, "Duloxetine associated with smoking cessation," Annals of Pharmacotherapy, vol. 39, no. 9, pp. 15781579, 2005.

[4] D. Tincello, M. Sculpher, R. Tunn et al., "Patient characteristics impacting health state index scores, measured by the EQ-5D of females with stress urinary incontinence symptoms," Value in Health, vol. 13, no. 1, pp. 112-118, 2010.

[5] R. C. Shelton, A. C. Andorn, C. H. Mallinckrodt et al., "Evidence for the efficacy of duloxetine in treating mild, moderate, and severe depression," International Clinical Psychopharmacology, vol. 22, no. 6, pp. 348-355, 2007.

[6] P. Soni, T. T. Mariappan, and U. C. Banerjee, "High-performance liquid chromatographic method for the simultaneous estimation of the key intermediates of duloxetine," Talanta, vol. 67, no. 5, pp. 975-978, 2005.

[7] P. J. Jansen, P. L. Oren, C. A. Kemp, S. R. Maple, and S. W. Baertschi, "Characterization of impurities formed by interaction of duloxetine $\mathrm{HCl}$ with enteric polymers hydroxypropyl methylcellulose acetate succinate and hydroxypropyl methylcellulose phthalate," Journal of Pharmaceutical Sciences, vol. 87, no. 1, pp. 81-85, 1998.

[8] G. S. Clarke, "The validation of analytical methods for drug substances and drug products in UK pharmaceutical laboratories," Journal of Pharmaceutical and Biomedical Analysis, vol. 12, no. 5, pp. 643-652, 1994. 


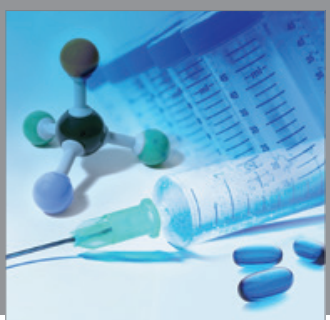

International Journal of

Medicinal Chemistry

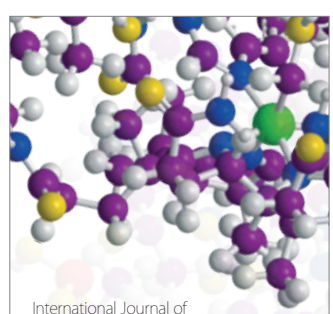

Carbohydrate Chemistry

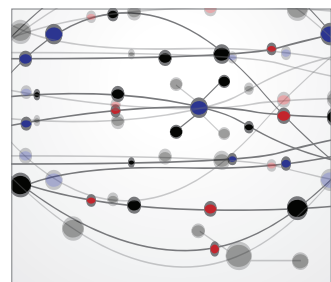

The Scientific World Journal
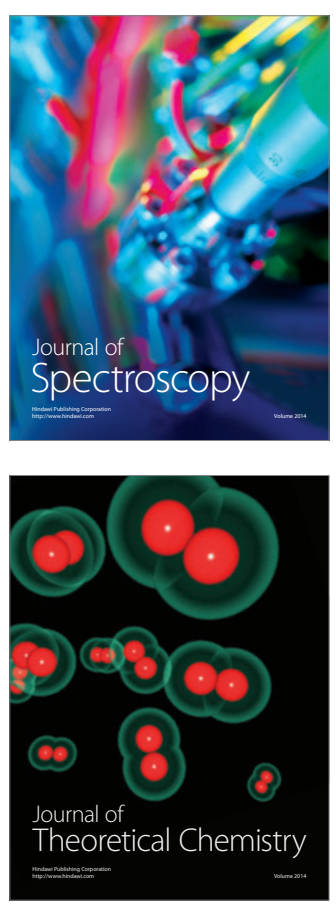
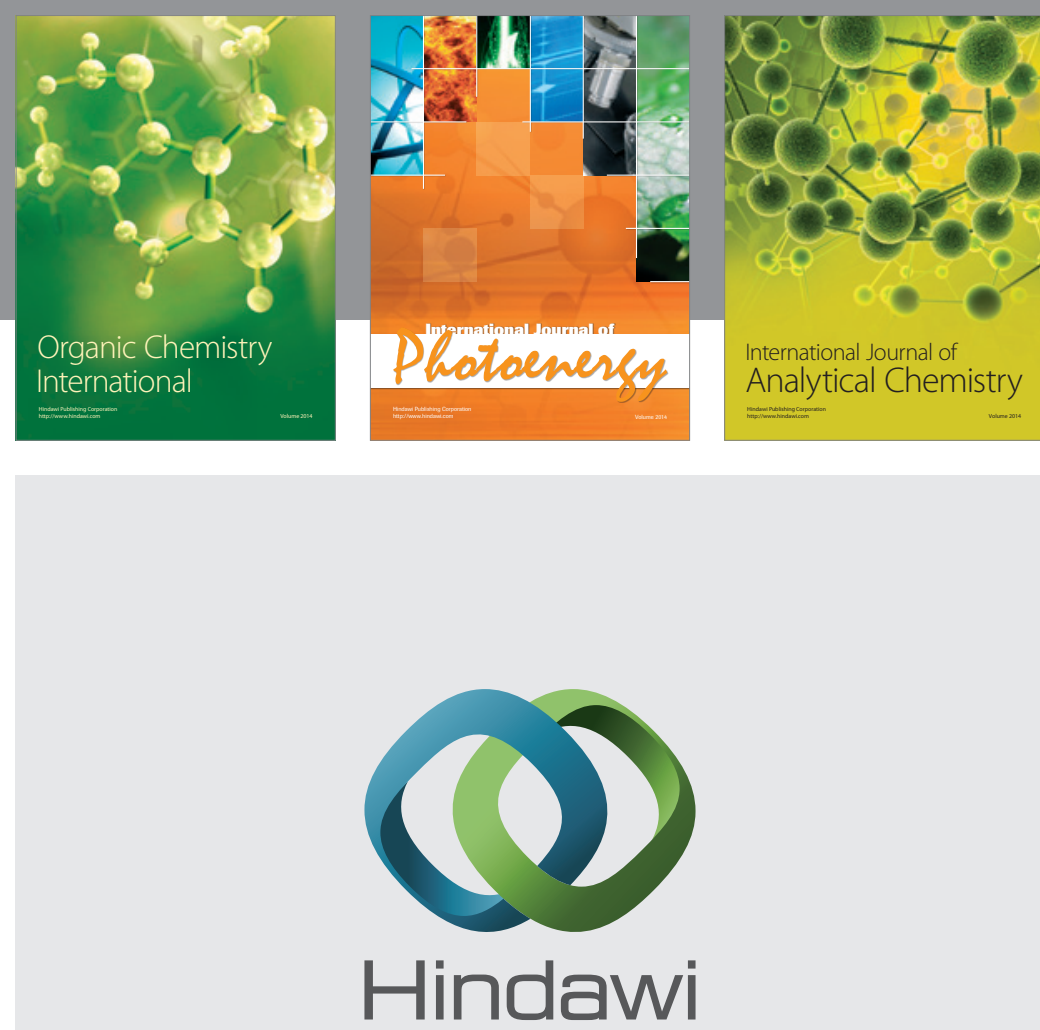

Submit your manuscripts at

http://www.hindawi.com
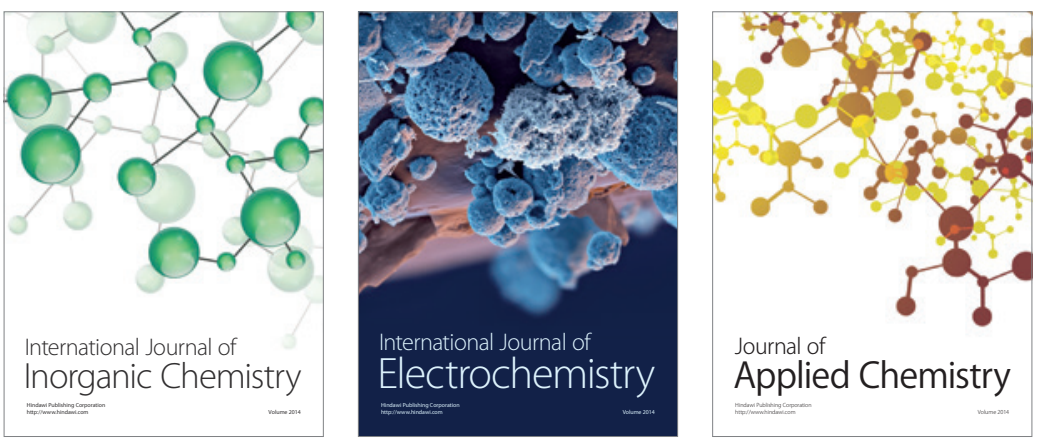

Journal of

Applied Chemistry
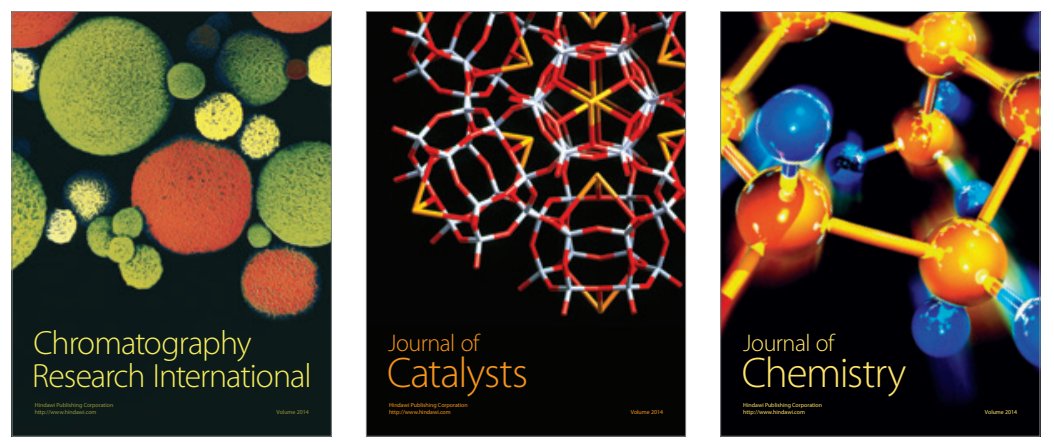
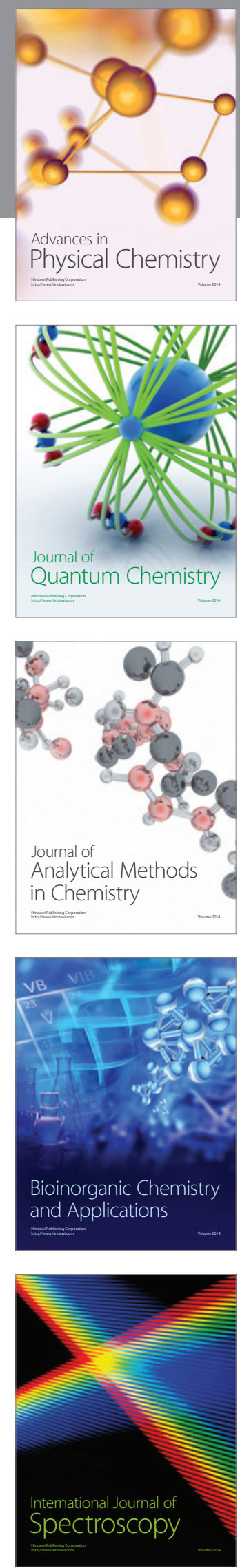